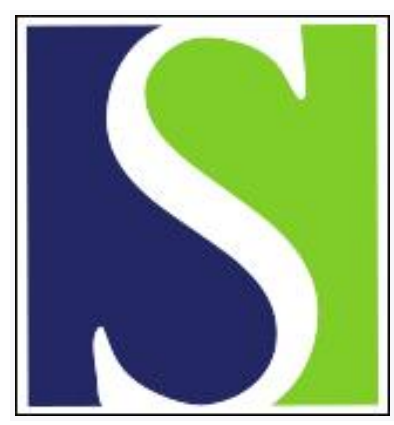

Scand J Work Environ Health 1986;12(2):154-155

https://doi.org/10.5271/sjweh.2163

Issue date: Apr 1986

Comment on the interpretation of effects caused by chronic trichloroethylene exposure.

by Kjellstrand $P$

Refers to the following texts of the Journal: 1980;6(1):40-47

1984;10(2):89-93

This article in PubMed: www.ncbi.nlm.nih.gov/pubmed/3726498

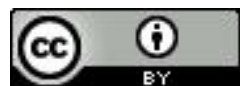




\section{Comment on the interpretation of effects caused by chronic trichloroethylene exposure}

In a letter to the Editor, published in volume 11, number 6 (pp 495-497) of the Scandinavian Journal of Work Environment \& Health, Drs A Gade \& HH Jensen, from the University of Copenhagen, referred to an article by myself and collaborators (4). The article is used by Gade \& Jensen as an example of how readily "state-dependent learning" can cause misinterpretation in experiments in which behavior is used in exploring effects on the central nervous system. An explanation of our results, based on the theory of state-dependent learning $(8,9)$, is put forward by Gade \& Jensen. However, I do not agree with their interpretation and would therefore like to make some comments to the letter in your column.

Our work was started with the intention of testing effects on the central nervous system from exposure to trichloroethylene. In the experiments we used a symetrical labyrinth developed by DS Olton (7) as a probe for spatial memory. The arms of the labyrinth are baited with sunflower seeds and the animals are allowed to seek and consume the seeds. This behavior is extremely sensitive to damage in the hippocampal area, while other parts of the brain seem not to be involved in any prominent way.

In short our results were that no effects on seedseeking behavior in the labyrinth could be seen during the solvent exposure or after it had been terminated. If, however, the animals were challenged by a second exposure several months after termination of the first, significant differences between the previously exposed animals and the controls were found.

During the compilation of the results, the possibility that differences in the learning situation of the exposed and control groups during one test could influence the results obtained during subsequent tests was considered. However, as a number of other posibilities seemed equally plausible, it was thought far too early to propose this possibility as a definite explanation. Instead the results were cautiously mentioned as "effects." No theory was presented in order to explain these effects.

Although no interpretation was given (contrary to what was suggested by Gade \& Jensen), the effects were described as "irreversible," as they persisted several months after the termination of the exposure. Furthermore they were considered as "covert," as they could not be revealed directly. Even if the interpretation given by Gade \& Jensen is correct, I think the effects can still be considered both as irreversible and covert. As I see things, this is a pure description with no intention to explain.
In order to shed some light on the problem of learning effects, a new experiment (which at that time was thought adequate) was designed. In it, in order to avoid any effects from learning, no testing in the maze was performed during the exposure but only at the end (as proposed by Gade \& Jensen in their letter). In the article describing these experiments the results were explained on the basis of "emotionality" (2). I still think this explanation is a close to correct interpretation, but Gade \& Jensen seem to have missed this article in their study of the literature.

The idea of "emotionality" actually arose from a quite different experiment, in which the animals (Mongolian gerbils) were trained to find a narrow cosy nest box, hidden in a large test box, under about $30 \mathrm{~cm}$ of shavings. The animals were trained until all of them dug their way into the nest box within $20 \mathrm{~s}$ after release on two consecutive days following the last training. We then studied how fast the animals forgot where the nest box was located. A curve describing "loss of memory" was obtained. On day 25 after the last training (and thus last visit in the test box), only two animals out of 16 found the nest box. However, the same animals (of which 14 had been removed before finding the nest box, most of them even before they had started digging) were again tested on day 26. Then 13 of them fulfilled the criteria. From this result it seems clear that most of the animals knew where the nest box was already on day 25 but that they nevertheless did not dig for it. The next day they were once again, through the "training" on day 25 , familiar with the test situation and thus started digging almost immediately for the nest box. Thus this test, designed for probing the memory, obviously probes something else.

In our first experiment (4) it was found that the exposed mice made more correct choices during the presumed unmasking condition (the second exposure) than on exposure-free days. Gade \& Jensen think this finding is "logically damaging for the validity of our interpretation." As it is not said in their letter why it is "logically damaging," I can only guess. I presume they mean that one would have expected the mice to find and eat more seeds on exposure-free days and thus to be "better'" on those days than on days when they had to cope with the second exposure. However, Gade \& Jensen do not consider that all of this assumption is human expectation with no value whatsoever when applied to mice, especially when it is not known what it is that is "better" or "worse." As seen from the previously described nest-box experiment, it might well be that the seed-seeking behavior in the maze has noth- 
ing to do with spatial memory but that it simply measures what is normally assayed through the "open field" test, ie, "emotionality" (1).

At this point the whole idea of developing a simple and reliable behavioral testing schedule for probing effects of solvent exposure on the central nervous system was questioned. This questioning was partly due to the fact that, even in our second experiment (2), learning could not be avoided, due to the inability to certify what actually caused the observed effects and thus what was learned. Results were also emerging which demonstrated that the inherent unreliability of long-time inhalation experiments is already from the beginning substantial (3). Furthermore direct evidence of a biochemical nature was beginning to be revealed $(5,6,10)$.

Actually the biochemical evidence rather strongly rejects the idea that learning in one form or another is responsible for the effects. Substantial biochemical alterations occur in the central nervous system, not only on marker proteins for the glial cell population, but also on the lipids. These alterations point toward some form of adaptation or damage due to the solvent exposure. On one hand it is of course only speculation that the behavioral effects (as I still prefer to call them) and the biochemical alterations are in any way causally related to each other. On the other I am indeed not prepared to explain the biochemical alterations as due to any form of learning. This would indeed be presumptuous, and I do not think that Gade \& Jensen mean it to be the case.

To summarize, I find the concept of state-dependent learning interesting. But I do not think that our experiments prove it to be the sole and correct explanation. I still prefer to regard what was seen as "effects," probably caused by "emotionality," and to await more substantial experimental confirmation before further theoretical picnics into the unknown are undertaken.

\section{References}

1. Archer J. Test for emotionality in rats and mice: A review. Anim Behav 21 (1973) 205-235.

2. Kjellstrand $\mathrm{P}$, Bjerkemo $\mathrm{M}$, Mortensen $\mathrm{I}$, Månsson $\mathrm{L}$, Lanke J, Holmquist B. Effects of long-term exposure to trichloroethylene on the behaviour of mongolian gerbils (Meriones Unguiculatus). J Toxicol Environ Health 8 (1981) 787-793.

3. Kjellstrand P, Holmquist B. Pitfalls in the interpretation of long term inhalation experiments. Toxicol Lett 21 (1984) 213-218.

4. Kjellstrand P, Lanke J, Bjerkemo M, Zetterqvist L, Månsson L. Irreversible effects of trichloroethylene exposure on the central nervous system. Scand J Work Environ Health 6 (1980) 40-47.

5. Kyrklund T, Alling C, Haglid K, Kjellstrand P. Chronic exposure to trichloroethylene: Lipid and acyle group composition in gerbil cerebral cortex and hippocampus. Neuro Toxicol 4 (1983) 35-42

6. Kyrklund T, Goracci G, Haglid K, Rosengren L, Porcellati G, Kjellstrand P. Chronic effects of trichloroethylene upon S-100 protein content and lipid composition in gerbil cerebellum. Scand $\mathrm{J}$ Work Environ Health 10 (1984) 80-93.

7. Olton DS, Samuelson RJ. Rememberance of places: Spatial memory in rats. J Exp Psychol Anim Behav Process 2 (1976) 97-116.

8. Overton DA. State-dependent learning produced by depressant and atrophine-like drugs. Psychopharmacology 10 (1966) 6-31.

9. Overton DA. Differential responding in a three choise maze controlled by three drug states. Psychopharmacology 11 (1967) 367-378.

10. Rosengren L. Astroglial reactions to organic solvent toxicity. Vasastadens Bokbinderi AB, Göteborg 1985. (Doctoral dissertation).

Per Kjellstrand, PhD

Department of Zoophysiology

University of Lund

Helgonavägen $3 \mathrm{~B}$

S-223 62 Lund Sweden 